\title{
An Electromechanical Co-Simulation Model Based on Lumped Parameter Model of Ball Screw Feed Drive System
}

\author{
Liang Luo ${ }^{1}$, Weimin Zhang ${ }^{1,2, a}$, Haonan Sui ${ }^{1}$ and Jürgen Fleischer ${ }^{2,3}$ \\ ${ }^{1}$ School of Mechanical Engineering, Tongji University, 201804 Shanghai, China. \\ ${ }^{2}$ Sino-German School for Postgraduated Studies (CDHK), Tongji University, 201804 Shanghai, China. \\ ${ }^{3}$ Institute of Production Science (wbk) , Karlsruhe Institute of Technology, 76131 Karlsruhe, Germany.
}

\begin{abstract}
The continuous search for efficiency put forward higher requests to the machine tool for high speed and high acceleration, which makes the large-size and lightweight-designed feed drive system more likely to produce vibration during high-speed and high-acceleration feed operation. Ball screw feed system is the most widely used linear drive system in the field of industrial automation. Electromechanical Co-Simulation for ball screw feed drive dynamics is an important technique for solving vibration problems occurs in the feed motion. In view of the shortcomings of the current dynamic simulation model in the study of vibration of ball screw feed drive system, taking a ball screw feed drive system test bench as an example, an electromechanical co-simulation model based on the lumped parameter model of ball screw feed drive system was built up in this paper. Firstly, based on the axial and rotation vibration integrated dynamic modeling method of ball screws, the lumped parameter model of ball screw feed system was established. Secondly, through the integration of the simulation model of semi-closed-loop cascade control system and the lumped parameter model of ball screw feed drive system, an electromechanical co-simulation model was built up. Simulation result shows that, the co-simulation model of ball screw feed drive system can predict the vibration occurs in the feed operation caused by the servo controller, ball screw feed system or the coupling between them.
\end{abstract}

\section{Introduction}

Ball screw feed system is the most widely used linear drive system in the field of industrial automation[1]. In order to enhance the velocity and accuracy of present systems further, current research focus on the vibration reduction and avoidance of the feed drive. Additional damping modules or structures are integrated in the feed drive system to achieve this goal, such as semi-active damping system and set point filtering etc. Active damping system only reacts once a vibration is present and set point filtering can lead to path deformation [2-4]. Another way to solve this problem is generate a smoother trajectory. For this purpose, numbers of trajectory algorithms are established and the frequency contents of the trajectory are discussed and compared $[5,6]$. The vibration caused by the trajectory is difficult to analysis on hardware because of the coupling of variety excitation sources. All these researches needs a simulation method to help the searchers or engineers to study or optimize the design and parameter setting of the feed drive system.

\footnotetext{
${ }^{\mathrm{a}}$ Corresponding author : iamt@tongji.edu.cn
} 
Finite element model of ball screw feed drive system can predict the accurate dynamic characteristics. However, it is difficult to integrate with the simulation model of servo control system. Lumped parameter model of ball screw feed dirve system can simplify the simulation model by reduce the number of degrees of freedom (DOF) of the whole system. More importantly, it can easily integrate with the simulation model of the servo control system. A reasonable simplification of the lumped parameter model is the key to accurately predict the vibration of feed drive system[7-9]. This paper in view of the shortcomings of the current modeling method in the vibration study of ball screw feed drive system, an electromechanical co-simulation method was established, which can be used to study the dynamic characteristics and vibration behavior of the feed drive system. Simulation result shows that, the co-simulation model of ball screw feed drive system can predict the vibration occurs in the feed operation.

\section{Lumped parameter model of ball screw feed system}

A typical ball screw feed system consists of a servomotor, coupling, ball screw, work table and base (Figure 1). The ball screw is supported by two sets of bearings, which are fixed to the base. The servomotor torque is transmitted through a coupling onto the ball screw shaft to drive the work table. The linear guideways constrain the movement of the work table in axial direction. The base is fixed on the machine bed or place on the ground. The transformation from the rotational movement of the screw shaft into the linear motion of the work table is realized by the ball screw system with its transmission ratio $i$, which is defined as the distance of travel $h$ during one revolution of the shaft as following :

$$
i=\frac{h}{2 \pi}
$$

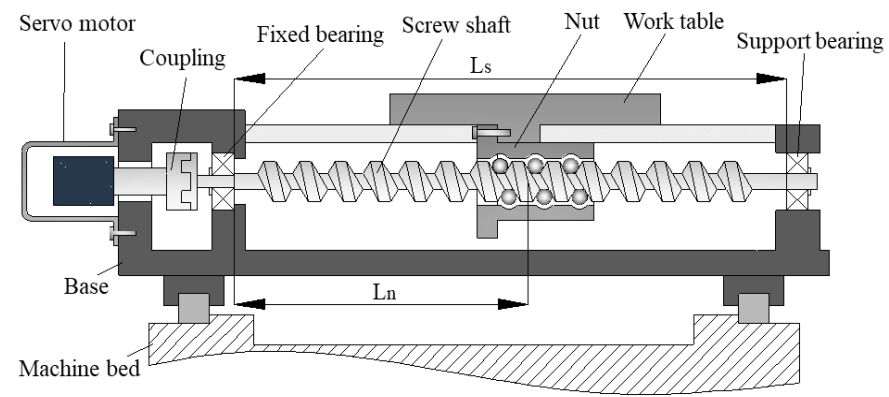

Figure 1. Typical structure of ball screw drive system

Low-order modes are the main factors affecting the dynamic characteristics of the ball screw feed drive system of machine tools. Typically the first axial or rotational mode of the ball screw show a dominant influence on the overall dynamics while the relevance of higher order modes for most technical applications is rather small[10]. The lumped parameter model of ball screw feed dirve system can reasonably reduce the DOF number of the simulation model while reserving the low-order modes of the system to simplify calculations. Figure 2 shows the lumped parameter model of a ball screw feed drive system. The influence of the shaft on the rotational mode and axial mode of the drive system are explicitly included into the lumped parameter model here. Therefore, the shaft is separated into two different branches, an axial and a rotational branch while the coupling once more is realized using constrained equations. Since all components are expressed by discrete springs and dampers, the rigidity values of shaft, coupling and bearing are combined to an overall axial $K_{a x}$ and rotational value $K_{\text {rot }}[11]$.

In this model the parameters are defined as following: rotary inertia of servo motor $J_{M}$, screw shaft side equivalent rotary inertia $J_{S}$, mass of base $M_{B}$, screw shaft side equivalent mass $M_{S}$, mass of the work table $M_{T}$, equivalent torsional rigidity $K_{\text {rot }}$, equivalent axial rigidity $K_{a x}$, rigidity of ball screw nut 
$K_{n}$, axial rigidity of base $K_{B}$, servo motor torsional damping $C_{M}$, equivalent torsional damping $C_{\text {rot }}$, screw shaft side damping $C_{S}$, ball screw nut damping $C_{n}$, equivalent axial damping $C_{a x}$, axial damping of the base $C_{B}$, axial damping of the guide $C_{g}$. The equivalent method of the lumped parameters of this model can refer to reference article [12].

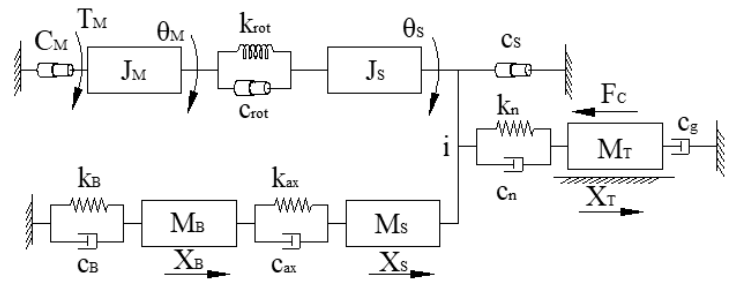

Figure 2. Lumped parameter model of ball screw feed system

According to the Lagrange's equations, with the independent coordinate system $\mathbf{q}$ and the generalized forces of the system $\mathbf{Q}$, the lumped mass model of ball screw feed system can be established as equation(2).

Where: $\quad \mathbf{q}=\left(\begin{array}{lllll}\theta_{M} & \theta_{S} & X_{B} & X_{S} & X_{T}\end{array}\right)^{T}$

$$
\mathbf{m} \ddot{\mathbf{q}}+\mathbf{c} \dot{\mathbf{q}}+\mathbf{k q}=\mathbf{Q}
$$

$$
\begin{aligned}
& \mathbf{Q}=\left(\begin{array}{lllll}
T_{M} & 0 & 0 & 0 & -F_{C}
\end{array}\right)^{T} \\
& \mathbf{m}=\left[\begin{array}{ccccc}
\mathrm{J}_{\mathrm{M}} & 0 & 0 & 0 & 0 \\
0 & \mathrm{~J}_{\mathrm{S}} & 0 & 0 & 0 \\
0 & 0 & \mathrm{M}_{\mathrm{B}} & 0 & 0 \\
0 & 0 & 0 & \mathrm{M}_{\mathrm{S}} & 0 \\
0 & 0 & 0 & 0 & \mathrm{M}_{\mathrm{T}}
\end{array}\right] \mathbf{k}=\left[\begin{array}{ccccc}
\mathrm{k}_{\text {rot }} & -\mathrm{k}_{\text {rot }} & 0 & 0 & 0 \\
-\mathrm{k}_{\text {rot }} & \mathrm{k}_{\text {rot }}-\mathrm{i}^{2} \mathrm{k}_{\mathrm{n}} & 0 & -\mathrm{ik}_{\mathrm{n}} & \mathrm{ik}_{\mathrm{n}} \\
0 & 0 & \mathrm{k}_{\mathrm{ax}}+\mathrm{k}_{\mathrm{B}} & -\mathrm{k}_{\mathrm{ax}} & 0 \\
0 & \mathrm{ik}_{\mathrm{n}} & -\mathrm{k}_{\mathrm{ax}} & \mathrm{k}_{\mathrm{ax}}+\mathrm{k}_{\mathrm{n}} & -\mathrm{k}_{\mathrm{n}} \\
0 & -\mathrm{ik}_{\mathrm{n}} & 0 & -\mathrm{k}_{\mathrm{n}} & \mathrm{k}_{\mathrm{n}}
\end{array}\right] \\
& \mathbf{c}=\left[\begin{array}{ccccc}
\mathrm{c}_{\mathrm{M}}+\mathrm{c}_{\text {rot }} & -\mathrm{c}_{\text {rot }} & 0 & 0 & 0 \\
-\mathrm{c}_{\text {rot }} & \mathrm{c}_{\text {rot }}-\mathrm{c}_{\mathrm{S}}-\mathrm{i}^{2} \mathrm{c}_{\mathrm{n}} & 0 & -\mathrm{ic}_{\mathrm{n}} & \mathrm{ic}_{\mathrm{n}} \\
0 & 0 & \mathrm{c}_{\mathrm{ax}}+\mathrm{c}_{\mathrm{B}} & -\mathrm{c}_{\mathrm{ax}} & 0 \\
0 & \mathrm{ic}_{\mathrm{n}} & -\mathrm{c}_{\mathrm{ax}} & \mathrm{c}_{\mathrm{ax}}+\mathrm{c}_{\mathrm{n}} & -\mathrm{c}_{\mathrm{n}} \\
0 & -\mathrm{ic}_{\mathrm{n}} & 0 & -\mathrm{c}_{\mathrm{n}} & \mathrm{c}_{\mathrm{n}}+\mathrm{c}_{\mathrm{g}}
\end{array}\right]
\end{aligned}
$$

\section{Co-simulation modeling of ball screw feed drive system}

Based on lumped parameter model of ball screw feed system and the simulation model of servo control system, an electromechanical co-simulation model of ball screw feed drive system are constructed. The co-simulation schematic of ball screw feed drive system is shown in Figure 3, while (a) is the simulation model of Semi-closed-loop cascade control system and (b) is the lumped parameter model of ball screw feed system. The cascade control structure is the most widely used in machine tool feed drives. As showning in Figure 3, the control system includes a P-position controller, a PI-velocity controller and a PI-current controller.

In Semi-closed-loop cascade control system, the servo motor feed back speed $\omega_{M}$ and the work table feed back position $X_{T}$ are calculated by the rotor position detected by the encoder on the servo motor. The input $P_{\text {ref }}$ is given by the CNC system according to the feed motion command, the input $P_{r e f}$ and work table feed back position $X_{T}$ are compared and the reference speed $\omega_{M-r e f}$ is given by the position controller. Then the reference speed $\omega_{M-r e f}$ is compared with the feed back speed $\omega_{M}$ and the velocity controller gives the reference current $i_{q \text {-ref }}$ for the $q$-axis and the reference current $i_{d-r e f}=0$ for $d$-axis of the stator. The three-phase current of the servo motor is detected and converts into $i_{d}$ and $i_{q}$ in $d-q$ coordinate system through the Clark and Park transformation. $i_{d-r e f}$ and $i_{q-r e f}$ are compared with the feedback $i_{d}$ and $i_{q}$ respectively, and the current controller calculates the given voltages $U_{d}$ and $U_{q}$ of the $d$ and $q$ axes, then they are converted into $U_{\alpha}$ and $U_{\beta}$ in the $\alpha-\beta$ coordinate system by Park inverse transformation. 
Finally, the SVPWM module generates 6-phase PWM to drive the three-phase inverter.The inverter outputs A-B-C three-phase voltage to servo motor stator, which generates rotating magnetic field and produce magnetic torque on the servo motor rotor. This magnetic torque is the output torque $T_{M}$ of the servo motor and drive the rotor to rotate under the dynamic relations of ball screw feed system.

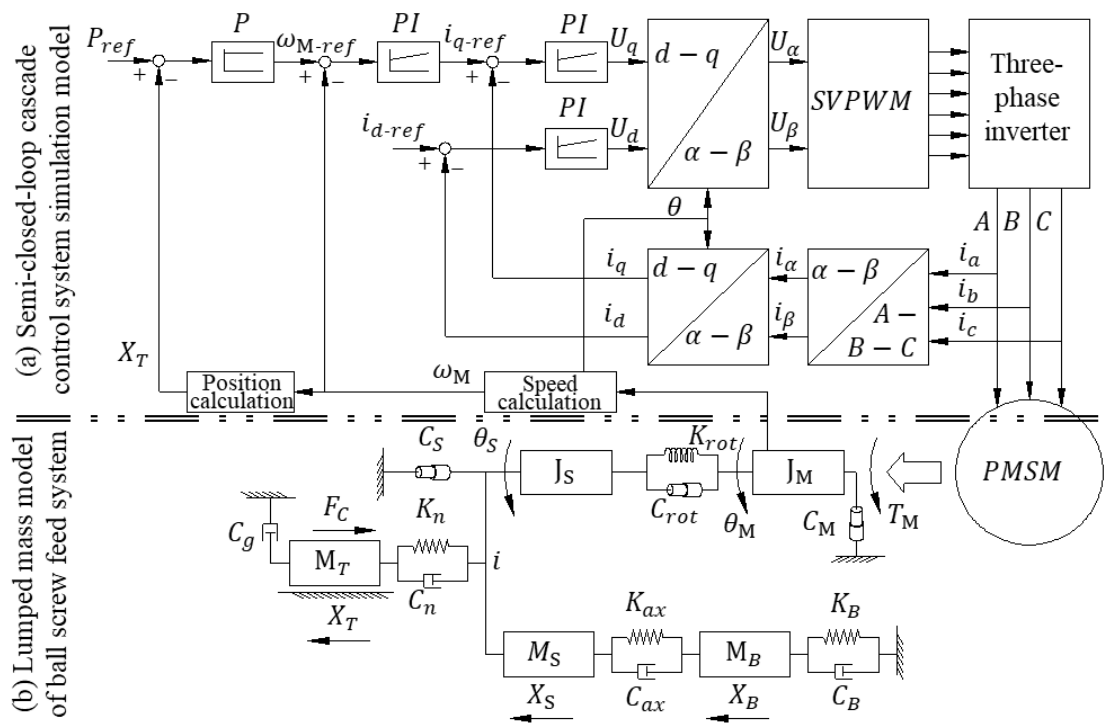

Figure 3. Schematic of ball screw feed drive system electromechanical co-simulation

The electromechanical co-simulation model of the semi-closed-loop controlled ball screw feed drive system is shown in Figure 4. The S_Cal module on the left side generate the trajectory command for the feed drive system according to the acceleration/deceleration strategy. Under the cascade control system the servo motor drive the ball screw accomplish the motion command accordingly.

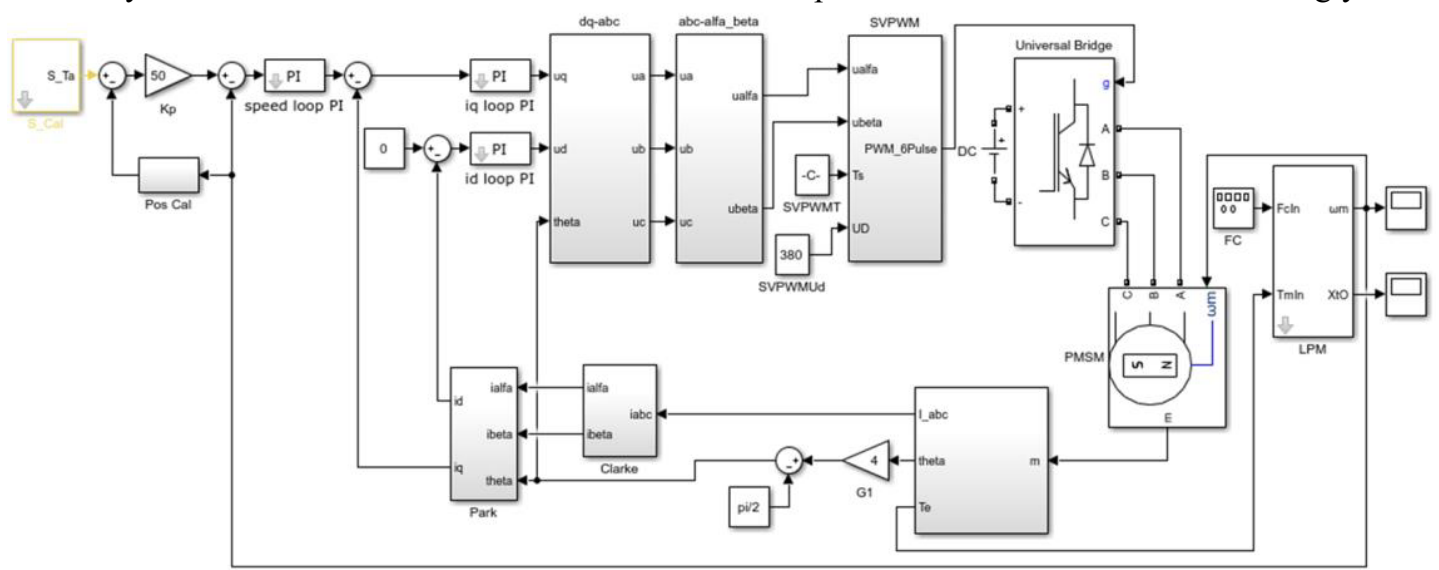

Figure 4. Electromechanical co-simulation model of half-closed ball screw feed system

\section{Simulation result of the electromechanical co-simulation model of ball screw feed drive system}

Take a ball screw feed drive system test bench of AMTC at Tongji Univesity as an example, an electromechanical co-simulation model as in figure 4 was built up. Table 1 are the simulation parameters used in the lumped parameter model of the test bench, which are calculated according to 
the specifications of the test bench. The specifications are either obtained from the manufacturers' catalogs, approximated from prior knowledge, or calculated from computer aided design (CAD).

Table 1. Simulation parameter used in the lumped parameter model of test bench

\begin{tabular}{|l|c|l|c|}
\hline \multicolumn{1}{|c|}{ Parameter of the component } & Value & \multicolumn{1}{c|}{ Parameter of the component } & Value \\
\hline Mass of work table $M_{T}(\mathrm{~kg})$ & 206 & Axial rigidity of base $K_{B}(\mathrm{~N} / \mathrm{m})$ & $1.09 \times 10^{8}$ \\
\hline Screw equivalent mass $M_{S}(\mathrm{~kg})$ & 11.28 & Screw equivalent rotary inertia $J_{S}\left(\mathrm{~kg} \cdot \mathrm{m}^{2}\right)$ & $1.7 \times 10^{-3}$ \\
\hline Rotary inertia of motor $J_{M}\left(\mathrm{~kg} \cdot \mathrm{m}^{2}\right)$ & $6.75 \times 10^{-3}$ & Rotary rigidity of screw $K_{\text {rot }}\left(\mathrm{N} \cdot \mathrm{m} \cdot \mathrm{rad}^{-1}\right)$ & $3.14 \times 10^{3}$ \\
\hline Axial rigidity of screw $K_{a x}(\mathrm{~N} / \mathrm{m})$ & $0.743 \times 10^{8}$ & Contact rigidity of the screw nut $K_{n}(\mathrm{~N} / \mathrm{m})$ & $9.8 \times 10^{7}$ \\
\hline Mass of base $M_{B}(\mathrm{~kg})$ & 3820 & & \\
\hline
\end{tabular}

Taking the servo motor torque as input and the axial acceleration of work table as output, the frequency response characteristics of the lumped parameter model of the test bench are analyzed. The bode diagram is shown in figure 5 , simulation result shows that the work table has 4-order natural frequencies, which are $26.2 \mathrm{~Hz}, 76.7 \mathrm{~Hz}, 247 \mathrm{~Hz}$ and $633 \mathrm{~Hz}$. Further study shows that, $76.7 \mathrm{~Hz}$ is the main axial vibration frequency of the work table, $26.2 \mathrm{~Hz}$ is the main axial vibration frequency of the base, $247 \mathrm{~Hz}$ and $633 \mathrm{~Hz}$ are the rotational vibration frequency.

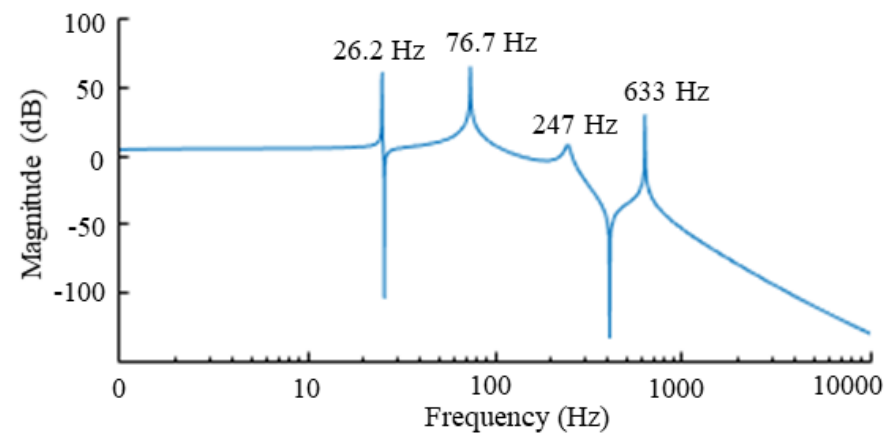

Figure 5. Bode diagram of the lumped parameter model of ball screw feed system

Other imprtant parameters, such as the parameters of the servo motor, the motion command parameters and the control parameters of the servo system, which are used in the electromechanical co-simulation model, are shown in table 2.

Table 2. Parameters of the servo system usd in the simulation model

\begin{tabular}{|l|c|l|c|}
\hline \multicolumn{1}{|c|}{ Parameter name } & Value & \multicolumn{1}{|c|}{ Parameter name } & Value \\
\hline Number of pole pairs & 4 & Inductance $L_{d}, L_{q}(H)$ & $8.15 \times 10^{-3}$ \\
\hline Stator resistance per phase $(\Omega)$ & 1.44 & Permanent magnetic flux $\Psi_{\mathrm{f}}(\mathrm{wb})$ & 0.21 \\
\hline Feeding displacement $(\mathrm{mm})$ & 400 & Position loop gain $k_{p}$ & 50 \\
\hline Maximum velocity $(\mathrm{mm} / \mathrm{s})$ & 400 & Velocity loop gain $k_{v}$ & 8 \\
\hline Maximum acceleration $\left(\mathrm{mm} / \mathrm{s}^{2}\right)$ & 2000 & Current loop gain $k_{i}$ & 30 \\
\hline Maximum jerk $\left(\mathrm{mm} / \mathrm{s}^{3}\right)$ & 20000 & & \\
\hline
\end{tabular}


Figures 6 shows the simulation result of the reference velocity and feedback velocity of the work table at the given operating conditions. (a) and (b) are the partial enlarged detail of constant velocity phase and accelerating phase of the feed motion. Velocity fluctuation can be obviously seen in the feedback velocity.

-.-· Reference velocity _ $\quad$ Feed back velocity

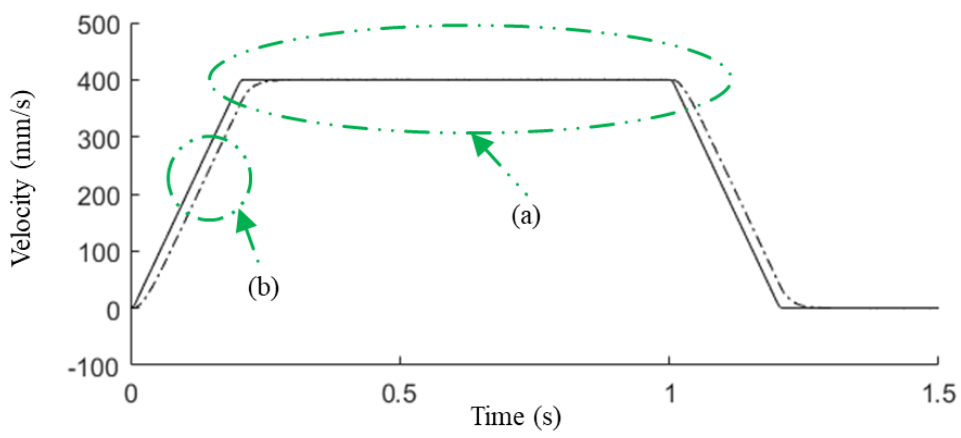

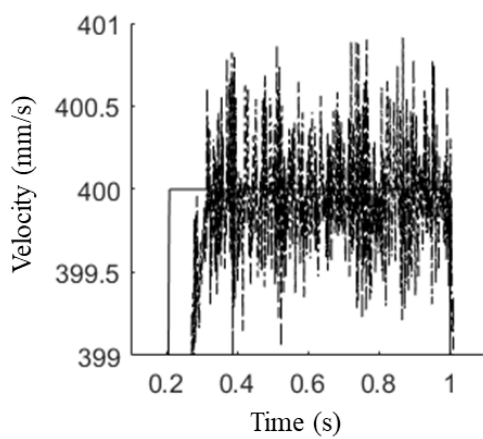

(a)

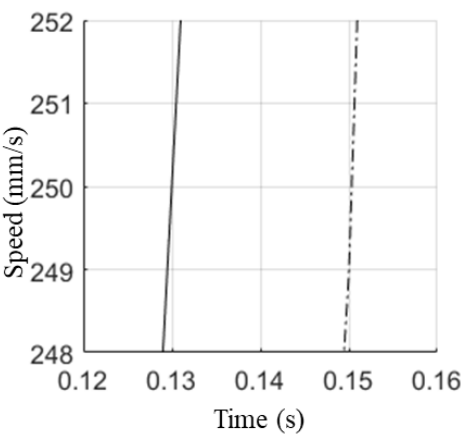

(b)

Figure 6. Simulation result of reference velocity and feedback velocity

Use the same operation parameters as seted in the simulaiton model, a feed motion experiment was conduct and the work table position was measured. Figure 7 shows frequency contents of the work table acceleration signals from the experimental and simulation result. Compare the simulation result with the experimental result, the co-simulation model of ball screw feed drive system can predict the vibration occurs in the feed operation. Both result show that in this case the second-order natural frequency (about $75 \mathrm{~Hz}$ ) but not the first-order natural frequency is the main factors inluencing the performance of feed drive system.

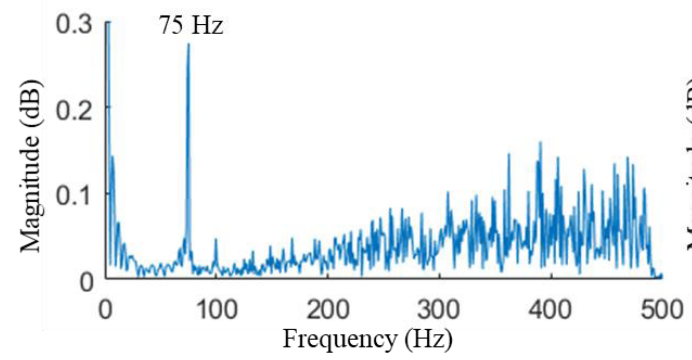

(a) Experimental result

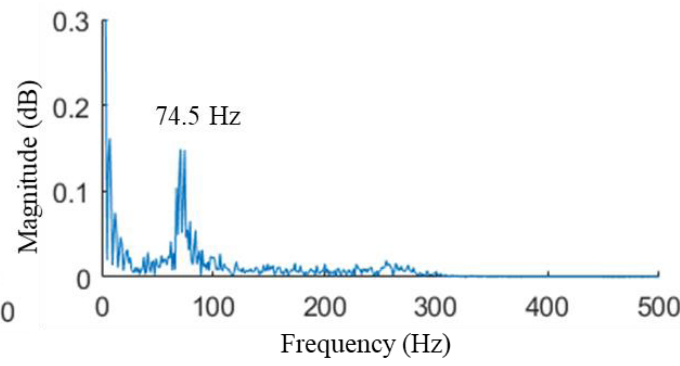

(b) Simulation result

Figure 7. Frequency contents of work table acceleration of the experimental and simulation result 


\section{Conclusion(s)}

In this paper an electromechanical co-simulation model of the ball screw feed drive system was constructed based on lumped parameter model of ball screw feed system, which can be used to study the dynamic characteristics and vibration behavior of the feed drive system. Taking a ball screw feed drive system test bench as an example, an electromechanical co-simulation model was built up. Simulation result shows that, the co-simulation model of ball screw feed drive system can predict the vibration occurs in the feed operation. Because of the integration of lumped parameter model into the detailed modeled cascade control simulation model, the electromechanical co-simulation of ball screw feed drive system could achieve a very good predictability for control performance and vibration behavior study of ball screw feed drive system, which may affact by the servo controller, ball screw feed system or the coupling between them.

\section{Acknowledgments}

This work is supported by the major national science and technology projects "high-end CNC machine tools and basic manufacturing equipment" (2012ZX04005031).

\section{References}

1. Y. Altintas, A. Verl, C. Brecher, L. Uriarte, G. Pritschow, CIRP ANN-MANUF TECHN, 60 (2011)

2. A. Verl, S. Frey, CIRP ANN-MANUF TECHN, 61 (2012)

3. A. Dietmair, A. Verl, MM Science Journal, (2009)

4. M. Yang, H. Hu, D. Xu, Electric Machines and Control, 16 (2012)

5. Y. Wang, D. Yang, R. Gai, S. Wang, S. Sun, INT J MACH TOOL MANU, 96 (2015)

6. Y. Jin, Y. He, J. Fu, J ZHEJIANG UNIV-SC B, 48 (2014)

7. X. Zhang, J. Zhang, W. Zhang, T. Liang, H. Liu, W. Zhao, MECH SYST SIGNAL PR, 98 (2018)

8. R. Sato, G. Tashiro, K. Shirase, Int. J. of Automation Technology, 9 (2015)

9. R. Sato, KEM, 516 (2012)

10. E C. Okwudire, Y. Altintas, J MECH DESIGN, 131 (2009)

11. S. Frey, A. Dadalau, A. Verl, Prod. Eng. Res. Devel., 6 (2012)

12. L. Luo, W. Zhang, M. Zhou, Mingjian, F. Jürgen, Transactions of the Chinese Society for Agricultural Machinery, 46 (2015) 